\title{
Design of Electric Drive for Vehicular Application Using Vector Control
}

\author{
Aditi Mohapatra ${ }^{1}$, K. Mohanraj ${ }^{2}$, Varun Avasthy ${ }^{3}$, Snehamoy Dhar $^{4}$ \\ ${ }^{I} P G$ scholar, Department of Electrical \& Electronics Engineering, SRM University, Tamil Nadu, India \\ ${ }^{2}$ Asst. Professor, Department of Electrical \& Electronics Engineering, SRM University, Tamil Nadu, India \\ ${ }^{3-4} P G$ scholar, Department of Electrical \& Electronics Engineering, SRM University, Tamil Nadu, India
}

\begin{abstract}
The field of electrical engineering is now finding itself being extensively used in vehicular technology. The current demands of high electrical power owing to increase in electrical loads in vehicles and the pressure on automobile makers to reduce emission levels have brought the usage of power converters and electric drives to the frontier. This paper aims to discuss the design and control scheme of an electric drive for vehicular application. The control systems are many; however, the use of vector control has been emphasized. A drive has been proposed and the simulated results show the achievement of speed control. Some light has also been spread on further improvements that can be encapsulated.
\end{abstract}

Keywords - Boost Chopper, Electric Drive, Vector Control, Voltage source inverter (VSI).

\section{Introduction}

Power electronics \& drives play a key role in vehicular technology in the current era where mechanical parts are gradually being replaced by electrical systems. Motors \& generators, being an integral part of a vehicle, need powerful drive systems. The rise of high power converters has given a new dimension to vehicles. The electric drive comprising of electrical motor/ generator set along with the power electronic converters have paved way for advanced vehicular design \& research which includes extracting wasted energy \& reusing it through regenerative braking. Electric Vehicles (EV) and Hybrid Electric Vehicles (HEVs) use electric propulsion systems which consist of electric motors, power converters, and electronic controllers.[1]. The power converter is used to supply the electric motor with proper voltage and current. The electronic controller commands the power converter by providing control signals to it, and then controls the operation of the electric motor to produce proper torque and speed, according to the command from the driver.[2].

Low end systems which have $14 \mathrm{~V}$ or $36 \mathrm{~V}$ DC bus are targeted for small displacement engines (which are less than 2.8 liters capacity).Medium voltage systems having $42 \mathrm{~V}$ or $150 \mathrm{~V}$ DC bus are suited to crankshaft mounted systems for light duty heavy vehicles including small trucks. These systems are used in mild hybrids. The high voltage systems (>200 V, typically $288-320 \mathrm{~V}$ ), are mostly used for fully hybrid applications which include idle start-stop, regenerative braking etc.[3].

Hybridization leads to downsized internal combustion engine power plants for equal vehicle performance with that of a conventional vehicle, while delivering improved fuel economy.[4].

\section{Proposed Idea}

HEVs combine more than one energy source for propulsion. In heat engine/battery hybrid systems, the mechanical power available from the heat engine is combined with the electrical energy stored in the battery to propel the vehicle. The systems also require an electric drivetrain to convert electrical energy into mechanical energy. The choice of electric propulsion systems of EVs \& HEVs depends on various factors like the driver's expectation (acceleration, driving speed, climbing capability, braking etc.),vehicle constraints and energy source.[5].

Differing from the industrial applications of motors, the motors used in EVs and HEVs usually require frequent starts and stops;high rates of acceleration/deceleration; high torque and low-speed hill climbing; lowtorque and high-speed cruising, and a very wide speed range of operation. Considering these factors, the motor chosen here is a three phase squirrel-cage induction motor, which has been proved to be a good performance motor, due to its ruggedness \& reliability. 


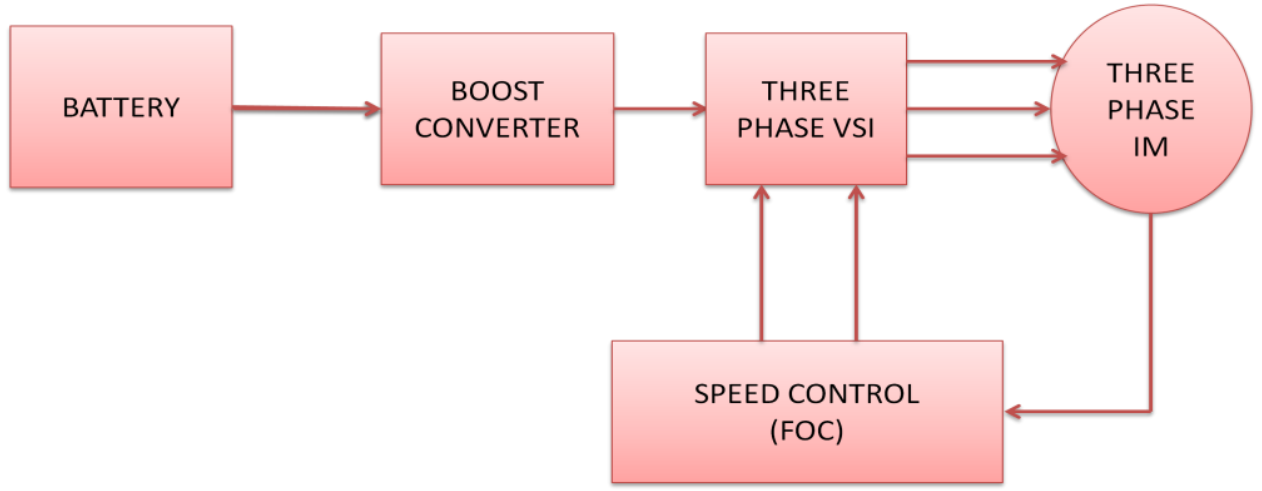

Fig 1. Proposed Drive \& Its Control Structure

Fig.1. represents an overall idea of the drive \& its control. The motor will be fed by the output from a VSI (Voltage Source Inverter) whose firing pulses will be controlled through pulse width modulation (PWM) technique. VSIs have the ability to operate efficiently in the range of $15-200 \%$ of motor operating speed. The inverter will receive DC power from a variable voltage source like a DC chopper and then adjust voltage and frequency according to motor requirements. The inverter utilizes solid-state switching devices to produce a series of constant voltage pulses of various widths to produce $\mathrm{AC}$ output. The timing and number of pulses are varied to produce varying frequency. The input to the inverter comes through a DC-DC Boost Converter which steps up the voltage from the battery pack .The battery packs generally employ Lead-acid batteries or Nickel Metal Hydride (NiMH) batteries. The speed control scheme used here is vector control or field oriented control.

\subsection{Boost Converter}

\section{Drive Design}

A boost DC/DC converter is a power converter with an output DC voltage greater than its input DC voltage. It is a class of switching-mode power supply containing at least two semiconductor switches (a diode and a switch) and at least one energy storage element (capacitor and/ or inductor). [6].Filters made of capacitors are normally added to the output of the converter to reduce output voltage ripple and the inductor connected in series with the input DC source in order to reduce the current ripple.

The smoothing inductor $\mathrm{L}$ is used to limit the current ripple. The filter capacitor $\mathrm{C}$ can restrict the output voltage ripples. The ripple current in the inductor is calculated by

neglecting the output voltage ripple. The capacitor must be able to keep the current supply at peak power. The output voltage ripple is a result of alternative current in the capacitor.

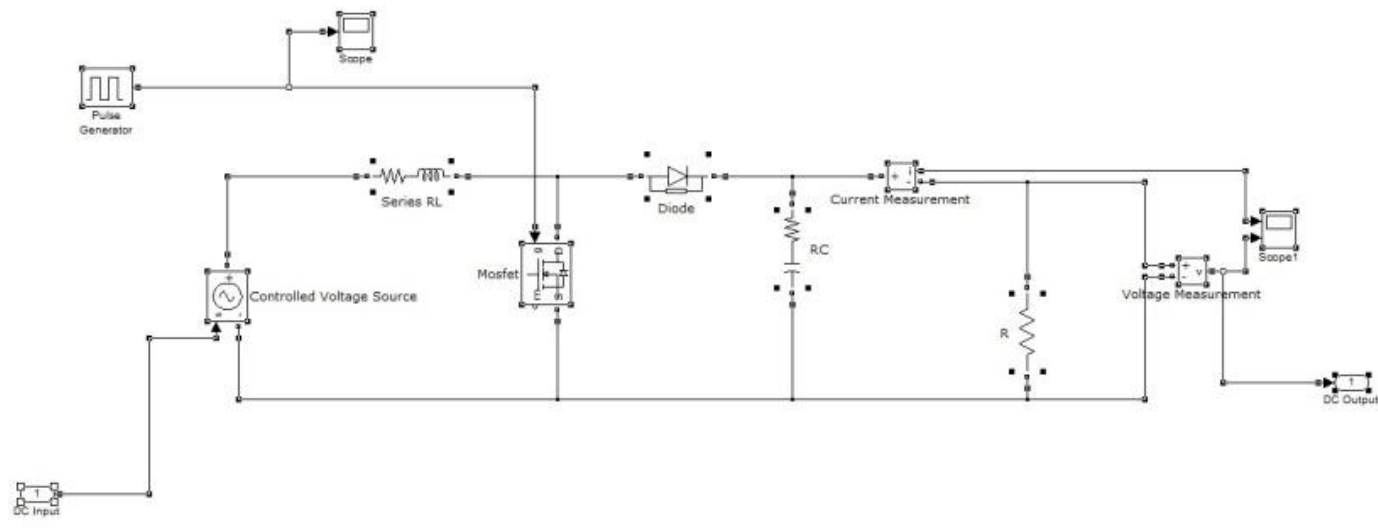

Fig.2. Simulink Circuit of the Boost Chopper

The values of various parameters are as follows:

$\mathrm{R}_{\mathrm{L}}=0.08 \Omega ; \mathrm{L}=100 \mu \mathrm{H}$

$\mathrm{R}_{\mathrm{C}}=5 \mathrm{~m} \Omega ; \mathrm{C}=2.15 \mu \mathrm{F} ; \mathrm{R}=10 \Omega$. 


\subsection{Design of Three Phase Voltage Source Inverter}

The output of the chopper is then fed to a three phase voltage source inverter (VSI).For a Wyeconnected Induction Motor, the load currents are generated by the line-to-neutral voltages of the inverter. Thus, the motor operation is controlled by line-to-neutral inverter voltages. The power switches in a given leg of the inverter must never both be in ON state, since this would cause a short- circuit. On the other hand, if both the switches on the same leg are in OFF state, then the potential of the corresponding output terminal is unknown to the control system of the inverter. Therefore, the inverter is controlled in such a way that, in a given leg, either the upper switch is ON \& the lower switch is OFF or vice versa. The phase-to-neutral voltages being fed to the induction motor is given by:-

$$
\begin{aligned}
& \mathrm{V}_{\mathrm{an}}=\left(\mathrm{V}_{\mathrm{dc}} / 3\right)(2 \mathrm{a}-\mathrm{b}-\mathrm{c}) \\
& \mathrm{V}_{\mathrm{bn}}=\left(\mathrm{V}_{\mathrm{dc}} / 3\right)(2 \mathrm{~b}-\mathrm{c}-\mathrm{a}) \\
& \mathrm{V}_{\mathrm{cn}}=\left(\mathrm{V}_{\mathrm{dc}} / 3\right)(2 \mathrm{c}-\mathrm{a}-\mathrm{b})
\end{aligned}
$$

Where $\mathrm{a}, \mathrm{b}, \mathrm{c}$ are the three phases; $\mathrm{V}_{\mathrm{dc}}$ is the DC supply voltage. The inverter is operated in 180 degree conduction mode where each switch conducts for 180 degrees. Three switches remain ON at any instant of time. There are 6 modes of operation in a cycle and duration of each mode is 60 degrees. The output of the three phase VSI is then fed to a $2.2 \mathrm{KW}$ three phase squirrel cage induction motor.

\subsection{Choice of Controller}

AC drives often feature several advantages over their DC counterparts. However control of AC drives is a complex issue. There are three main schemes: the scalar V/f control, the field oriented control (FOC) and the direct torque control (DTC), each one with several variants. In these control schemes, the use of an inverter, the controller blocks and feedback signal processing is involved. Besides the induction motor (IM) itself is not as simple as the DC motor with separated field. Perhaps, due to such complexity, the study of AC drives is performed on dynamic simulations.

In hybrid electric vehicles (HEVs), both the combustion engine and the electrical motor contribute to the propulsion force to the wheels of the vehicle. However, conventional control of IM such as constant V/f control is not accurate enough to be used in HEVs because HEVs application needs more precise torque tracking compared to other industrial drive systems. Furthermore, this torque tracking is sensitive to change of electrical machine parameters. Therefore, in HEVs, an electric motor with a rapid and accurate torque tracking over different speed range is needed.

For choosing an appropriate FOC for controlling the IM in HEV, some considerations must be kept in the picture, such as the basic cost, the maintenance cost, the precision of control, the speed of response, reliability etc.

In vector control with direct rotor flux orientation, two hall sensors are employed for obtaining the rotor flux directly. Hall sensors are too vulnerable, especially in an application like HEV. Furthermore, these hall sensors are placed inside the IM, so changing them becomes more complicated compared to a sensor which is placed outside the machine. In contrast, in Indirect Vector Control, the rotor flux is calculated from slip speed. This slip speed is easily calculated by the rotor speed which is obtained by a simple speed sensor that is placed on the electrical machine shaft. Therefore, the drive becomes simpler and more reliable with less cost. Thus, the indirect vector control for this project is chosen.

\subsubsection{Theory of Indirect Field Oriented Control}

The principle of FOC is to make a condition that the AC motor works similar to a DC motor and produces optimal torque. In DC motor, the mmf which is produced by the armature current $i_{a}$ is maintained at a right angle to the field flux which is produced by the stator, by employing the commutator and brushes. In contrast with $\mathrm{AC}$ machine, both the fields in DC machine are stationary. The electromagnetic torque $T_{e}$ which is developed in a DC machine is given by

$$
T_{e}=K i_{a} i_{f}
$$

Where $K$ is a constant, $i_{a} \& i_{f}$ are armature and field currents respectively. These space vectors are orthogonal in nature and hence, are decoupled. This means that when torque is controlled by controlling current $i_{a}$, the field flux $\psi_{f}$ isn't affected. And we get fast transient response and high torque/ampere ratio with the rated field flux. Because of decoupling, when the field current $i_{f}$ is controlled, it affects the field flux $\psi_{f}$ only

but not the $\psi_{a}$ flux. If a step change in torque is desired, then a simple step change in the armature current would fulfill the objective. But due to inherent coupling problem, an induction motor cannot generally give such a fast response. Thus, the aim of FOC is to maintain the angle between armature mmf and the field $\mathrm{mmf}$ at 90 degrees for producing optimal torque. 
Thus, in vector control of induction motor, the stator current space vector $i_{s}(t)$ is divided into $\mathrm{d} \& \mathrm{q}$ rotating axis .The stator phase currents are controlled in a way that $i_{q s}$ delivers the desired torque while $i_{d s}$ maintains the desired rotor flux density at the rated value. The field orientation of currents is essential under all operating conditions in a vector-controlled drive.Induction Motor space vectors rotate synchronously at speed $\omega_{\mathrm{e}}$

Transferring three-phase variables (voltage, current, and flux) into a stationary stator-based dq frame doesn't change the alternate characteristics of the variable with time.AC quantities are somewhat inconvenient for control purposes. For instance, control systems are represented by block diagrams in which the variables are time-varying DC signals. Therefore, another transformation is necessary, which allows the conversion of the AC dq components of the motor vectors into DC variables. To do this, a transformation is conducted from a stationary reference frame, dq, to the so-called excitation reference frame DQ, which rotates with angular speed $\omega$, in the same direction as stator mmf. As a result, in the steady state, coordinates of motor vectors in the new reference frame don't vary with time. The voltage vector of the stator in excitation reference frame can be expressed as :

$$
v_{S}^{e}=v_{S}^{S} e^{-j \omega t}
$$

Three-phase to dq stationary reference frame is given by:

$$
\left[\begin{array}{c}
v_{d s}^{s} \\
v_{q s}^{s}
\end{array}\right]=\left[\begin{array}{ccc}
1 & -\frac{1}{2} & -\frac{1}{2} \\
0 & \frac{\sqrt{3}}{2} & -\frac{\sqrt{3}}{2}
\end{array}\right]\left[\begin{array}{c}
v_{a s} \\
v_{b s} \\
v_{c s}
\end{array}\right]
$$
frame is:

Considering $e^{-j \omega t}=\cos (\omega \mathrm{t})-\sin (\omega \mathrm{t})$, the components of stator current on synchronously rotating dq

$$
\left[\begin{array}{l}
i_{d s}^{e} \\
i_{q s}^{e}
\end{array}\right]=\left[\begin{array}{cc}
\cos \theta_{r} & \sin \theta_{r} \\
-\sin \theta_{r} & \cos \theta_{r}
\end{array}\right]\left[\begin{array}{l}
i_{d s}^{s} \\
i_{q s}^{s}
\end{array}\right]
$$

The $i_{q s}{ }^{e}$ or $i_{T}$ which is known as torque producing component and the $i_{d s}{ }^{e}$ or $i_{f}$ which is known as flux producing component, have only dc components in steady state condition. Thus, they are ideal to be used as control variables. Furthermore, the rotor flux linkage $\lambda_{r}$ is moving at a speed equal to the synchronous speed. Therefore, the speed error which is obtained from the difference between the reference speed $\omega_{\mathrm{m}}{ }^{*}$ and the actual speed $\omega_{\mathrm{m}}$, is used to generate the reference torque $\mathrm{T}^{*} . \theta_{f}$ is the flux angle and $i_{a s}, i_{b s}, i_{c s}$ are the three phase stator currents. During rotor flux orientation

$$
\lambda_{Q R}^{e}=0
$$

Thus,

$$
\lambda_{D R}^{e}=\lambda_{r}
$$

Where $\lambda_{D R}^{e} \& \lambda_{Q R}^{e}$ are the components of the vector of rotor flux in the excitation frame. The torque is determined by the following equation:

$$
T=K_{T} \lambda_{D R}^{e} i_{Q S}^{e} \text { N.m }
$$

Where $i_{Q S}^{e}$ is the q component of the vector of the stator current in the excitation reference frame and $K_{T}$ is the torque constant and can be expressed by:

$$
K_{T}=\frac{P}{3} \frac{L_{m}}{L_{m}+L_{r}}
$$




\section{Implementation Of Vector Control In Matlab}

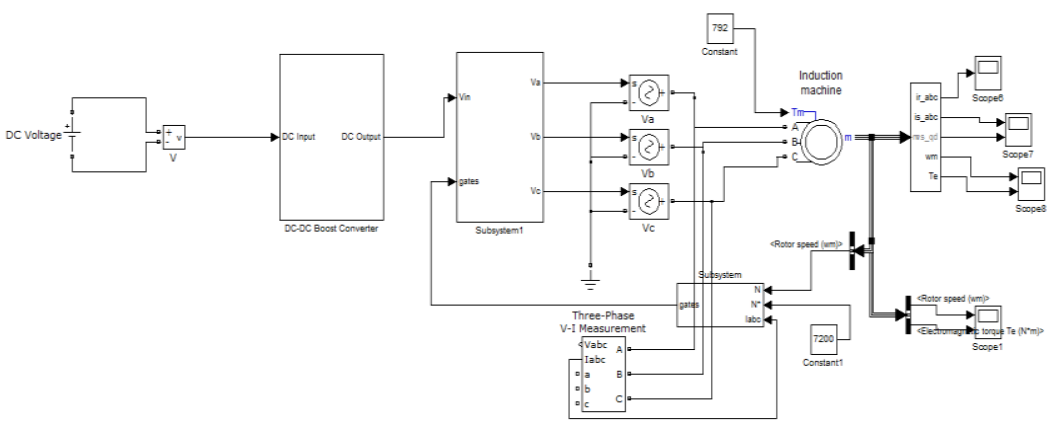

Fig.3. Simulink Block of the Complete Drive System

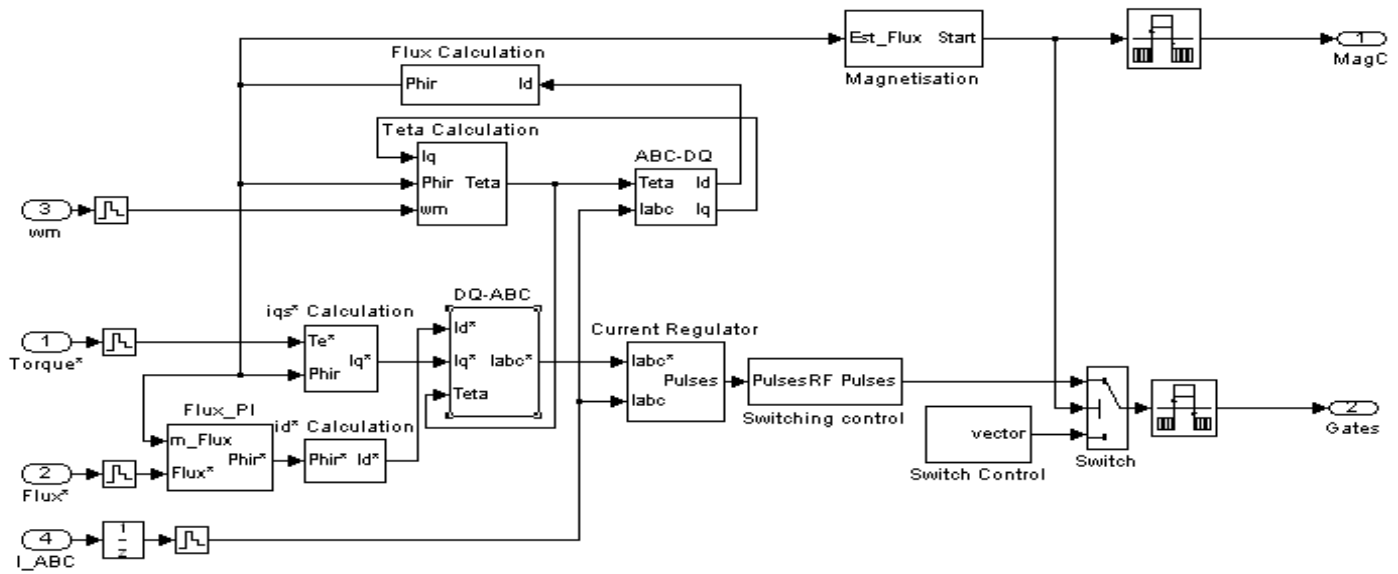

Fig.4. Final Pulse Generation

\section{Discussion Of Simulation Results}

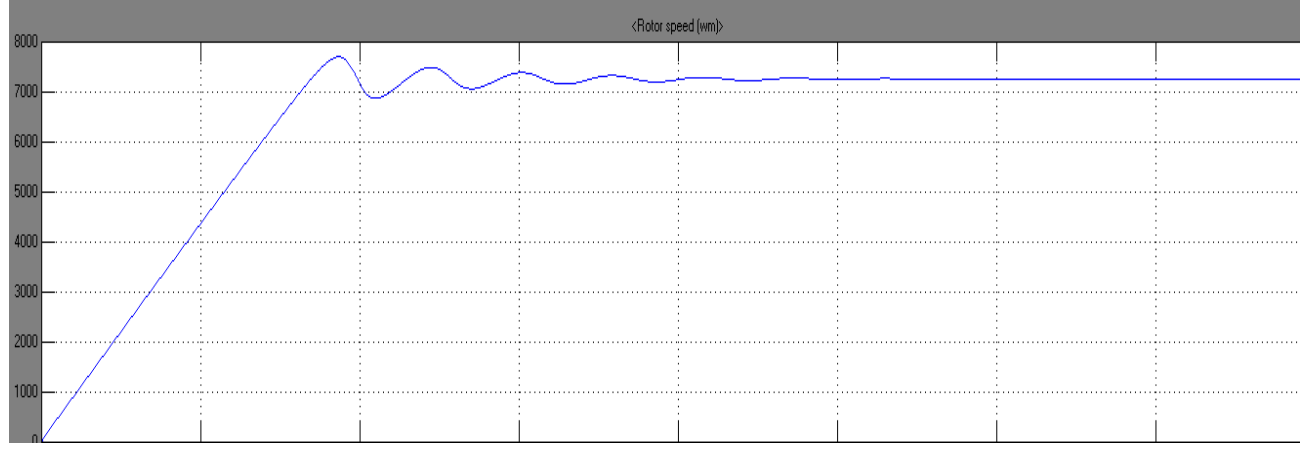

Fig.6.Speed Control Characteristics at 5000rpm

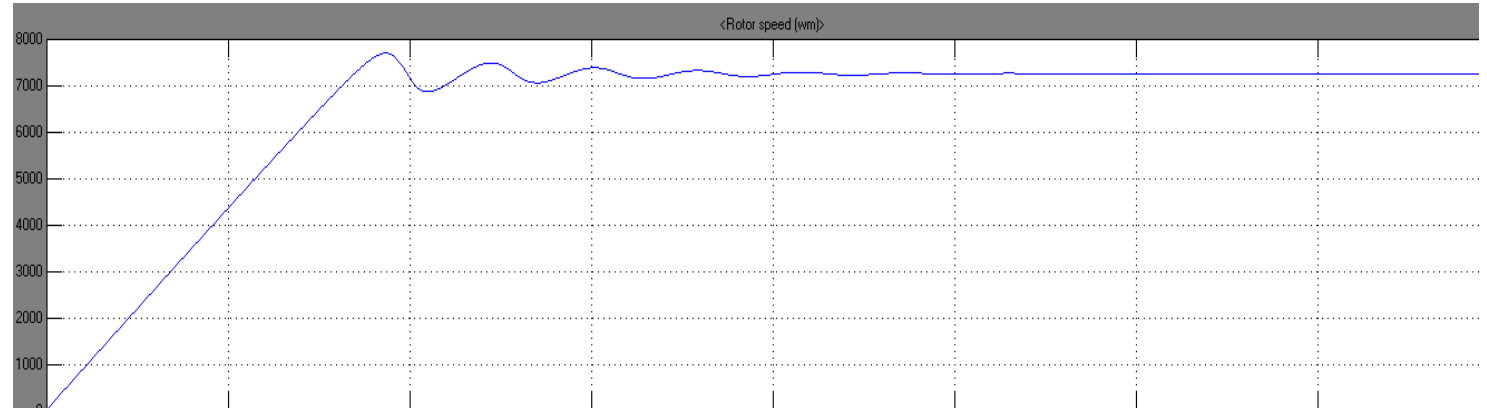

Fig.7.Speed Control Characteristics at 6000rpm 


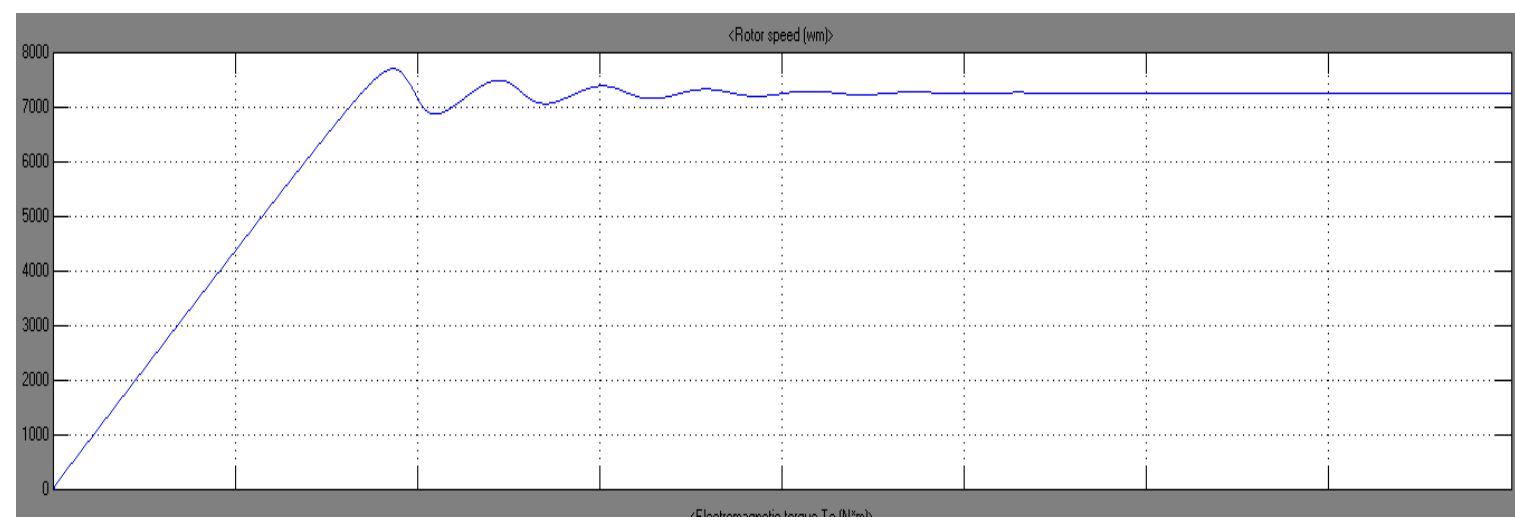

Fig.8.Speed Control Characteristics at 7000rpm

Rating of the Induction Motor $=2.2 \mathrm{KW}$

Reference speed set for the Induction Motor $=7000 \mathrm{rpm}$

Initial Overshoot in Speed $=8000 \mathrm{rpm}$

Speed at which motor attains equilibrium $=7255 \mathrm{rpm}$

Initial Torque Overshoot $=1500 \mathrm{Nm}$

Final Running Torque of the motor $=790 \mathrm{Nm}$

Time taken to achieve speed control $=2.5$ Seconds

Deviation from the required speed $=3.64 \%$

\section{Conclusion}

An electric drive was designed to meet the requirements of a hybrid electric vehicle. Study of various speed control schemes has proved that indirect field-oriented control is a superior speed control technique because of faster speed response and the user can avoid the use of hall sensors. Thus, we can see that the motor speed settles down at 7255rpm in a span of 2.5 seconds.. However, due to factors like nonlinearities in the system, harmonics present in the output of the converter/inverter section, the derived speed deviates from the required speed by $3.64 \%$.which is manageable. The overall response of the drive is stable after the initial overshoot, which is natural in any system. Further improvements can be done to decrease the speed error.

\section{References}

[1] Ali Emadi, Y.J.Lee, K.Rajashekara, "Power Electronics \& Motor Drives in Electric, Hybrid Electric \& Plug-In Hybrid Electric Vehicles", IEEE Transactions on Industrial Electronics, Vol.55, No.6,June 2008.

[2] Ali Emadi, Mehrdad Ehsani, John M. Miller, “Vehicular Electric Power Systems", 1" Indian Reprint,2010. New York: Marcel Dekker.

[3] Mehrdad Ehsani,Yimin Gao, Ali Emadi, “Modern Electric, Hybrid Electric, and Fuel Cell Vehicles”, Chap:6,2 $2^{\text {nd }}$ ed. Boca Raton, New York: CRC Press, Taylor \& Francis Group,2004.

[4] Cheng Shukang,Li Cuiping, Chai feng, "Research on Induction Motor for Mini Electric Vehicles", International Conference on Future Electrical Power \& Energy Systems, Science Direct, Elsevier,2012.

[5] Y.Jeong,"Modeling \& Control of a Boost Chopper Linked to AC Drive System for Hybrid Electric Vehicles”, IEEE ISBN No.1-42440714-1, 2007.

[6] K.Asano, H.Ohtani,E.Sato, S.Sasaki, "High Performance Motor Drive Technologies for Hybrid Vehicles", Toyota Central R\&D Labs, Inc., Toyota Motor Corporation,2007.

[7] Wenguang Yan,Vadin Utkin, Giorgio Rizzoni, “Power Flow Control for a Series Hybrid Vehicle”,IEEE ISIE Conference Croatia,2005.

[8] Goh Tech Chiang,Jun-ichi Itoh, "DC/DC Converter Functionality in a Three Phase Indirect Matrix Converter”, IEEE Transactions on Power Electronics, Vol.26, No.5, May 2011.

[9] Brigitte Hauke, “Basic Converter's Power Stage”, Texas Instruments Application Report, Revised, July 2010.

[10] Bimal K.Bose “Modern Power Electronics \& AC Drives”, Revised Edition,2001.

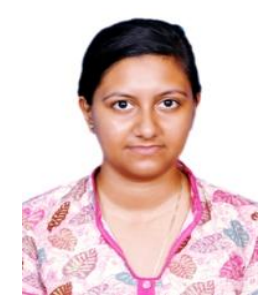

Aditi Mohapatra completed her Bachelor in Technology from Biju Patnaik University of Technology, Odisha, India in Electrical and Electronics Engineering in the year 2010 and is currently a PG Scholar in Power Electronics and Drives from ,SRM University, Chennai, Tamil Nadu, India. Her area of interests include Induction Motor and Synchronous Motor Drives, their control, and Hybrid Electric Vehicles. 

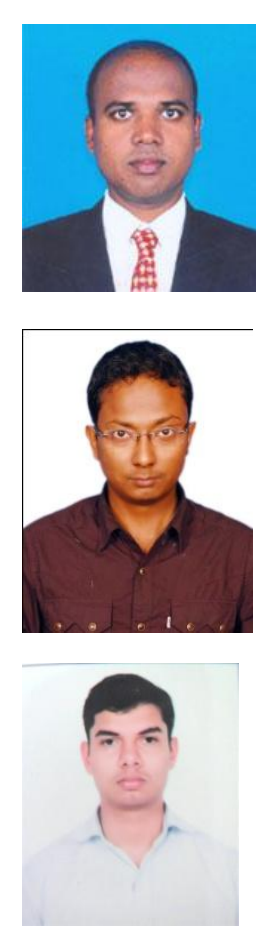

Mr.K.Mohanraj is currently working as Assistant Prof. in SRM University, Chennai. He completed his B.E in Electrical Engineering from Madras University \& M.E. in Power Electronics and Drives from Anna University in 2004\& is currently pursuing his PhD from SRM University. He has 3 international journal publications\& has presented papers in more than 10 international conferences. His areas of interest include Fault Analysis in Induction Motors, Power Converters \& AC drives.

Snehamoy Dhar was born in West Bengal, India on April 14, 1987. He has received his B.Tech degree in Electronics \& Communication Engineering in the year of 2009 from West Bengal University of Technology, Kolkata. He has two years of Industrial experience as an Assistant Project Engineer in Electrical Distribution project (RGGVY) in Meghalaya, India. He is presently pursuing his M.Tech degree in Power Electronics and Drives from SRM University, Chennai. His area of interest involves Power Electronics, Solar Photovoltaic Power system, Inverter, Harmonic Analysis and Reduction.

Varun Avasthy was born in Uttar Pradesh, India on August 26, 1988. He has received his B.Tech degree in Electrical \& Electronics Engineering in the year of 2010 from Uttar Pradesh Technical University, Lucknow. He is presently pursuing his M.Tech degree in Power Electronics and Drives from SRM University, Chennai. His area of interest involves in Power Electronics, Grid Interactive Solar Photovoltaic Power system. 